\title{
Greatest International ANtiinfective Trial (GIANT) with moxifloxacin in the treatment of acute exacerbation of chronic bronchitis: subanalysis of Chinese data of a global, multicenter, noninterventional study
}

This article was published in the following Dove Press journal:

Clinical Epidemiology

10 March 2010

Number of times this article has been viewed

\author{
Yulin Feng' \\ Faguang Jin ${ }^{2}$ \\ Shuang $\mathrm{Mu}^{3}$ \\ Hong Shen ${ }^{4}$ \\ Xiaohong Yang ${ }^{5}$ \\ Yuling Wang 6 \\ Zhenshan Wang ${ }^{7}$ \\ Yingjun Kong ${ }^{8}$ \\ Zuke Xiao' \\ Qiming Feng ${ }^{10}$
}

'Respiratory Department, West China Hospital, Sichuan University,

China; ${ }^{2}$ Respiratory Department,

Tang Du Hospital, China; ${ }^{3}$ Respiratory

Department, Peking University

People's Hospital, China; ${ }^{4}$ Emergency

Department, The General Hospital of the People's Liberation Army, China;

${ }^{5}$ Respiratory Department, Xinjiang

People's Hospital, China; 'Respiratory

Department, Shi Jiazhuang First

Hospital, China; ${ }^{7}$ Respiratory

Department, The Second Affiliated

Hospital of Dalian Medical University,

China; ${ }^{8}$ Respiratory Department,

The First Clinical College of Harbin Medical University, China;

${ }^{9}$ Respiratory Department, The Jiangxi Provincial People's Hospital, China;

${ }^{10}$ Emergency Department, Shanghai

Sixth People's Hospital, China
Correspondence:Yulin Feng

No. 37, Guoxue Alley, Chengdu, Sichuan

Province, China

Email fengyulinIII5@I26.com
Background and objective: A single infective acute exacerbation of chronic bronchitis (AECB) has a sustained effect on health status. Although a number of clinical investigations have demonstrated the efficacy of antibiotics in AECB, increased bacterial resistance has caused concern about the efficacy of currently available antibiotic therapies. This subanalysis of a global noninterventional study aimed to evaluate the impact of AECB on the patient and the community and the effectiveness and safety of a treatment with moxifloxacin (MXF) tablets in daily life clinical practice in China.

Methods: This prospective, noninterventional, noncontrolled, multicenter observational study, which started in China in April 2004 and ended in February 2007, was part of the global GIANT study. Patients with a diagnosis of mild to severe AECB were treated with MXF tablets $400 \mathrm{mg}$ for a period at the physician's discretion. The observation period for each patient covered a complete treatment period with MXF. For each patient, the physician documented data at an initial visit (baseline) and at least one follow-up visit. Data were collected on demography, diagnosis of infection, pretreatment, concomitant diseases and medications, MXF therapy, course of symptoms during investigations, and final assessment of therapy with respect to MXF.

Results: In the Chinese subset of the GIANT study, a total of 11,377 patients were included in the intention-to-treat/safety population. At the end of the initial treatment period, improvement and recovery from infection was observed for $98.6 \%(\mathrm{n}=11,217 / 11,377)$ and $92.6 \%$ $(n=10,540 / 11,377)$ of all patients. After 1 week of treatment, $76.3 \%(n=8681 / 11,377)$ of patients had recovered. Median time until improvement and recovery was 3.0 and 6.0 days, respectively. Correspondingly, in $95.8 \%(\mathrm{n}=10,903 / 11,377)$ of all patients, overall effectiveness during the initial treatment period with MXF was assessed as "very good" or "good". Compared with the last AECB, the number of days with impact on daily-life activities and the number of nights with sleep disturbances decreased from 3.0 to 2.0 (median) and from 2.0 to 1.0 (median), respectively. In general, MXF treatment was very well tolerated, with physician's overall assessment of tolerability as "good" or "very good" in $95.2 \%(\mathrm{n}=10,834 / 11,377)$ of patients. The incidence rate of adverse events and adverse drug reactions was $0.82 \%(\mathrm{n}=93)$ and $0.67 \%(\mathrm{n}=76)$, respectively. The most frequent adverse events were gastrointestinal disorders such as nausea $(0.31 \%, \mathrm{n}=35)$ and vomiting $(0.19 \%, n=22)$, which were mostly drug-related. One individual serious adverse event (dyspnea) occurred during the observation period, which was assessed as drug-related.

Conclusion: MXF was effective and well tolerated in patients suffering from AECB. The fast speed of the drug's onset of action was associated with rapid improvement of clinical parameters.

Keywords: China, moxifloxacin, chronic bronchitis, acute exacerbation, GIANT 


\section{Introduction}

Chronic bronchitis is a clinical diagnosis in patients presenting with persistent cough and excessive secretion of mucus on most days for at least 3 consecutive months in 2 consecutive years. ${ }^{1}$ Patients presenting clinical symptom of chronic bronchitis are a heterogeneous group in terms of the severity of their condition. Airflow obstruction is present to a variable degree, and emphysema may or may not be present.

A single infective exacerbation of chronic bronchitis (AECB) has a sustained effect on health status. The recovery period is long even in patients who have no further exacerbations. $^{2}$ These episodes contribute to morbidity, mortality and diminished quality of life, ${ }^{3}$ but their cause can be difficult to identify and may include air pollutants, allergens and viruses as well as bacterial pathogens. The bacterial species isolated most frequently from the sputum of patients with AECB include Haemophilus influenzae, Streptococcus pneumoniae and Moraxella catarrhalis. ${ }^{4}$

A number of clinical investigations have demonstrated the efficacy of antibiotics in AECB, but the causative pathogen is only rarely identified in clinical practice. Treatment is therefore usually empirical, and needs to cover the most likely pathogens. Increased bacterial resistance has caused concern about the efficacy of currently available antibiotic therapies. Failure to treat appropriately with an antibacterial that eradicates the pathogen quickly is associated with persistent airway inflammation, and can increase the requirement for hospitalization and repeated course of therapy.

Moxifloxacin is an 8-metoxifluoroquinolone with a broad spectrum of antibacterial activity; it is effective against both Gram-positive and Gram-negative pathogens, atypical pathogens and anaerobic bacteria, including many drug-resistant bacteria.

The data presented here are the Chinese data from GIANT, a global noninterventional study, aimed to evaluate the impact of AECB on the patient and the community and the effectiveness and safety of treatment with moxifloxacin in daily routine practice.

\section{Materials and methods Study design}

The data presented were a subanalysis on the Chinese data of the global GIANT postmarketing surveillance study - a prospective, noninterventional, noncontrolled, multicenter study. The study was carried out in China between April 2004 and February 2007. Patients with a diagnosis of mild to severe AECB who are prescribed moxifloxacin in daily life clinical practice were documented. Moxifloxacin administration and dose were decided by the attending physician. The observation period for each patient covered a complete treatment period with moxifloxacin. For each patient, the physician documented data at an initial visit (baseline) and at least one follow-up visit. No additional diagnostic or monitoring procedures were applied to patients. Observation parameters are demography, AECB history (including treatment of last AECB, and impact on the patient), current chronic bronchitis, general and specific concomitant diseases, moxifloxacin therapy, and concomitant medication. Effectiveness parameters include course of symptoms, duration until improvement and recovery, and overall assessment of effectiveness by patient and physician. Safety parameters include adverse events (AEs), adverse drug reactions (ADRs) and global assessment of tolerability.

Based on the symptom assessments by the physician at the start of therapy and at the last follow-up visit, calculations were performed for the course of the symptoms fever, dyspnea, cough, sputum volume, chest discomfort, and fatigue as well as for the course of sleep disturbance. A symptom was categorized as "relieved" if assessed as "none" or "no" at the last follow-up, as "improved" if assessed with a better category at the last follow-up compared to the start of therapy, as "unchanged" if assessments did not change, and as "worsened" assessed with a worse category at the last follow-up compared to the start of therapy. Safety analysis included tabulation of type (using MedDRA coding) and frequency of all drug-related and nondrug-related AEs. The seriousness, action taken, and outcome of events were described.

\section{Data analysis}

The analysis was based on the intention-to-treat (ITT) population. Descriptive analyses of the data were performed using summary statistics for categorical and quantitative data. Continuous data were described by mean, SD, minimum, 1, 5, 25, 75, 95, 99 percentiles, median, maximum, and number of nonmissing values. In addition, continuous data were categorized in a clinically meaningful way. Categorical data including categories of continuous data were presented in frequency tables. If applicable, stratified frequency tables contained column percent and row percent. Number of patients with missing data was presented as a separate category. Percentages were calculated as a proportion of each category including the category missing values. In defined cases, percentages were calculated based on non-missing values or for a predefined category. In summary tables of the report, the category "missing" was in general not listed. 


\section{Study population}

ITT population/safety population

The definitions of the ITT and safety population were identical in this study. Patients were included in the ITT/safety population if it was documented that they took at least one dose of moxifloxacin. A total of 11,454 patients were enrolled in this observational study. The first patient entered the study on April 24, 2004. The last visit of the last patient was on February 13, 2007. In summary, a total of 11,377 patients were valid for the ITT/safety population.

\section{Results \\ Demographics}

11,377 patients were included in the statistical analysis. More male than female patients ( $\mathrm{n}=7486 / 11,377,65.8 \%$ vs $\mathrm{n}=3885 / 11,377,34.1 \%$ ) were documented during the study (6 patients had missing data on sex). Almost all patients were described to be of Asian origin ( $n=11,280 / 11,377$, $99.1 \%$ ). Age ranged from 15 to 103 years, mean age was $59.7 \pm 15.1$ years, and median age was 60.9 years. Male patients were on average (mean) 4.2 years older than female patients. Mean height was $167.1 \pm 7.6 \mathrm{~cm}$ and mean weight $63.5 \pm 10.5 \mathrm{~kg}$. Mean body mass index was $22.6 \pm$ $2.9 \mathrm{~kg} / \mathrm{m}^{2}$. About half of all patients $(\mathrm{n}=5905 / 11,377$, $51.9 \%)$ were current smokers $(\mathrm{n}=3106 / 11,377,27.3 \%)$ or past smokers $(\mathrm{n}=2799 / 11,377,24.6 \%)$, whereas $47.5 \%$ $(\mathrm{n}=5404 / 11,377)$ of patients were nonsmokers. Chronic bronchitis was diagnosed in 16.2\% $(\mathrm{n}=1846 / 11,377)$, $38.0 \%(\mathrm{n}=4238 / 11,377), 21.4 \%(\mathrm{n}=2430 / 11,377)$, and $22.4 \%(\mathrm{n}=2553 / 11,377)$ of the patients $<1$ year, 1 to 5 years, $>5$ to 10 years, and $>10$ years prior to study start, respectively (Table 1).

At baseline (initial visit), the majority of patients $(n=7350 / 11,377,64.6 \%)$ had one or more concomitant diseases relevant to AECB. The most frequently reported concomitant diseases by system organ class were cardiac diseases $(n=4255 / 11,377,37.4 \%)$, thoracic and/or mediastinal diseases $(\mathrm{n}=1775 / 11,377,15.6 \%)$, and infections ( $\mathrm{n}=1638 / 11,377,14.4 \%)$. More than one-quarter of the patients $(n=3220 / 11,377,28.3 \%)$ suffered from only one concomitant disease, whereas two or more concomitant diseases were found in $36.3 \%(n=4130 / 11,377)$ of patients. The most frequently reported concomitant pulmonary diseases were COPD ( $\mathrm{n}=4574 / 11,377,40.2 \%)$, followed by emphysema $(\mathrm{n}=3550 / 11,377,31.2 \%)$. The most prevalent concomitant cardiac diseases were cor pulmonale $(\mathrm{n}=1729 / 11,377$, $15.2 \%)$, cardiac ischemia $(n=1229 / 11,377,10.8 \%)$, and heart insufficiency $(\mathrm{n}=990 / 11,377,8.7 \%)$ (Figure 1).
Table I Demographic and other baseline characteristics

\begin{tabular}{|c|c|}
\hline Patients $(\mathbf{N}=11,377)$ & \\
\hline \multicolumn{2}{|l|}{ Sex } \\
\hline Male & $7486(65.8 \%)$ \\
\hline Female & 3885 (34.1\%) \\
\hline Missing & $6(0.1 \%)$ \\
\hline \multicolumn{2}{|l|}{ Race } \\
\hline Asian & II,280 (99.1\%) \\
\hline Other & $93(0.8 \%)$ \\
\hline Missing & $4(<0.1)$ \\
\hline \multicolumn{2}{|l|}{ Age (years) } \\
\hline$<45$ & $2028(17.8 \%)$ \\
\hline$\geq 45$ and $<65$ & $4626(40.7 \%)$ \\
\hline$\geq 65$ & 4494 (39.5\%) \\
\hline Missing & $229(2.0 \%)$ \\
\hline \multicolumn{2}{|l|}{ Nicotine consumption } \\
\hline Smoker & $5905(51.9 \%)$ \\
\hline Nonsmoker & $5404(47.5 \%)$ \\
\hline \multicolumn{2}{|c|}{ Duration of chronic bronchitis } \\
\hline$<$ I year & $1846(16.2 \%)$ \\
\hline I to 5 years & $4238(38.0 \%)$ \\
\hline$>5$ to 10 years & $2430(21.4 \%)$ \\
\hline$>10$ years & $2553(22.4 \%)$ \\
\hline \multicolumn{2}{|l|}{ Severity } \\
\hline Mild & $2319(20.4 \%)$ \\
\hline Moderate & $7394(65.0 \%)$ \\
\hline Severe & 1608 (14.1\%) \\
\hline
\end{tabular}

\section{Treatments}

Almost all patients started therapy with the approved dose of $400 \mathrm{mg}$ moxifloxacin once daily $(\mathrm{n}=11,331 / 11,377,99.6 \%)$. In five individual patients, an initial daily dose of $600 \mathrm{mg}(\mathrm{n}=1)$ or $800 \mathrm{mg}(\mathrm{n}=4)$ was given. Moxifloxacin was administered to the majority of patients for periods of $5(n=4619 / 11,377,40.6 \%)$, $6(n=2947 / 11,377,25.9 \%)$, and $7(n=1468 / 11,377,12.9 \%)$ days. Following stratified analyses, duration of therapy was found to be related to the severity of infection: moxifloxacin was administered for a longer period in patients with severe AECB ( 7 days, median) than in patients with moderate ( 6 days, median) or mild exacerbation (5 days, median). The most commonly administered concomitant medications relevant to the chronic bronchitis treatment were "mucolytics" $(n=2958 / 11,377$, 26.0\%), followed by "xanthines" ( $\mathrm{n}=1991 / 11,377,17.5 \%)$, anti-infectives $(\mathrm{n}=1172 / 11,377,10.3 \%)$.

\section{Effectiveness results}

At the end of the observation period, mainly positive assessments were given: for $95.8 \%(n=10,903 / 11,377)$ of patients 
Heart

insufficiency

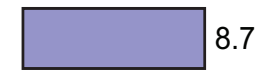

8.7

$\mathrm{n}=11377$

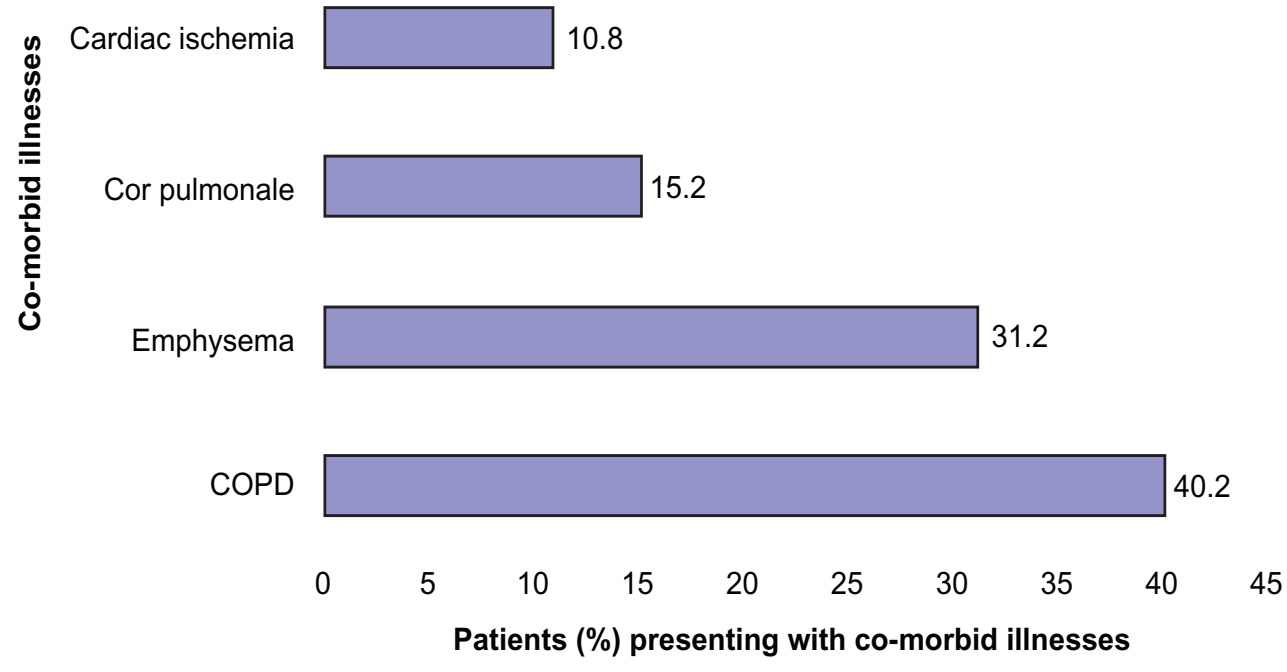

Figure I Concomitant diseases occurring in study patients.

effectiveness was rated as "very good" or "good", while in $2.7 \%(n=303 / 11,377)$ and $0.7 \%(n=83 / 11,377)$ of patients effectiveness was rated as "sufficient" and "insufficient". Physicians were "very satisfied" or "satisfied" with the therapeutic effect in $98.1 \%(n=11,165 / 11,377)$ of patients. Therapeutic effect was rated as "not satisfied" for $1.8 \%(n=205 / 11,377)$ of patients. $97.4 \%(n=11,079 / 11,377)$ of the patients were "very satisfied" or "satisfied" with the therapeutic effect, while $2.5 \%(n=284 / 11,377)$ were "not satisfied" (Table 2).

The mean duration until improvement was $3.2 \pm 1.4$ days, whereas the mean duration until recovery was $6.2 \pm 2.2$ days, with medians of 3.0 and 6.0 days, respectively. The range for improvement was from 1 to 23 days and for recovery from 1 to 30 days. For approximately three-quarters of patients ( $\mathrm{n}=8248 / 11,377,72.5 \%)$, an improvement was seen within 3 days of treatment; in $93.8 \%(n=10,672 / 11,377)$ of patients, an improvement was seen within 5 days of therapy. More than three-quarters $(n=8681 / 11,377,76.3 \%)$ of all patients, recovered within 1 week of treatment (Figure 2).

For most patients, only one follow-up visit was documented. The last follow-up visit (first or second follow-up visit) was 7.0 days (median) after start of moxifloxacin therapy. Patient symptoms documented at start of moxifloxacin therapy reflected a typical profile associated with AECB. At the last follow-up visit, a relevant reduction in all recorded symptoms was observed compared with the initial visit. The majority of patients experienced a change in symptoms from the initial visit to the last follow-up visit, described as "relieved" or "improved" (Figure 3).

\section{Tolerability results}

An overall assessment by physicians of tolerability of moxifloxacin treatment for each patient was made at the end of the initial treatment period. In general, moxifloxacin treatment was considered to be well tolerated, rated in $95.2 \%(n=10,834 / 11,377)$ of patients as "very good" and "good". For $4.2 \%(n=481 / 11,377)$ of patients, tolerability was assessed to be "sufficient". The category "insufficient" was given for $0.4 \%(n=50 / 11,377)$ of patients. No relevant differences were found when data were stratified by sex, age, AECB symptoms, and severity of the disorder (Figure 4).

Table 2 Effectiveness results at the end of the observation period

\begin{tabular}{|c|c|c|c|c|c|}
\hline & \multicolumn{5}{|c|}{ Physician's effectiveness assessment } \\
\hline & $\begin{array}{l}\text { Very } \\
\text { good }\end{array}$ & Good & Sufficient & Insufficient & Missing \\
\hline & $\begin{array}{l}6685 \\
(58.8 \%)\end{array}$ & $\begin{array}{l}4218 \\
(37.1 \%)\end{array}$ & $\begin{array}{l}303 \\
(2.7 \%)\end{array}$ & $\begin{array}{l}83 \\
(0.7 \%)\end{array}$ & $\begin{array}{l}88 \\
(0.8 \%)\end{array}$ \\
\hline & \multicolumn{5}{|c|}{ Physician's assessment of therapeutic effect } \\
\hline \multirow[t]{5}{*}{$\begin{array}{l}\text { Total } \\
(\mathrm{N}=\mid \mathrm{I}, 377)\end{array}$} & $\begin{array}{l}\text { Very } \\
\text { satisfied }\end{array}$ & Satisfied & $\begin{array}{l}\text { Not } \\
\text { satisfied }\end{array}$ & Missing & \\
\hline & $\begin{array}{l}5945 \\
(52.3 \%)\end{array}$ & $\begin{array}{l}5220 \\
(45.9 \%)\end{array}$ & $\begin{array}{l}205 \\
(1.8 \%)\end{array}$ & $\begin{array}{l}7 \\
(0.1 \%)\end{array}$ & \\
\hline & \multicolumn{5}{|c|}{ Patient's assessment of therapeutic effect } \\
\hline & $\begin{array}{l}\text { Very } \\
\text { satisfied }\end{array}$ & Satisfied & $\begin{array}{l}\text { Not } \\
\text { satisfied }\end{array}$ & Missing & \\
\hline & $\begin{array}{l}5574 \\
(49.0 \%)\end{array}$ & $\begin{array}{l}5505 \\
(48.4 \%)\end{array}$ & $\begin{array}{l}287 \\
(2.5 \%)\end{array}$ & $\begin{array}{l}11 \\
(0.1 \%)\end{array}$ & \\
\hline
\end{tabular}


$\mathrm{n}=11217 / 11377$

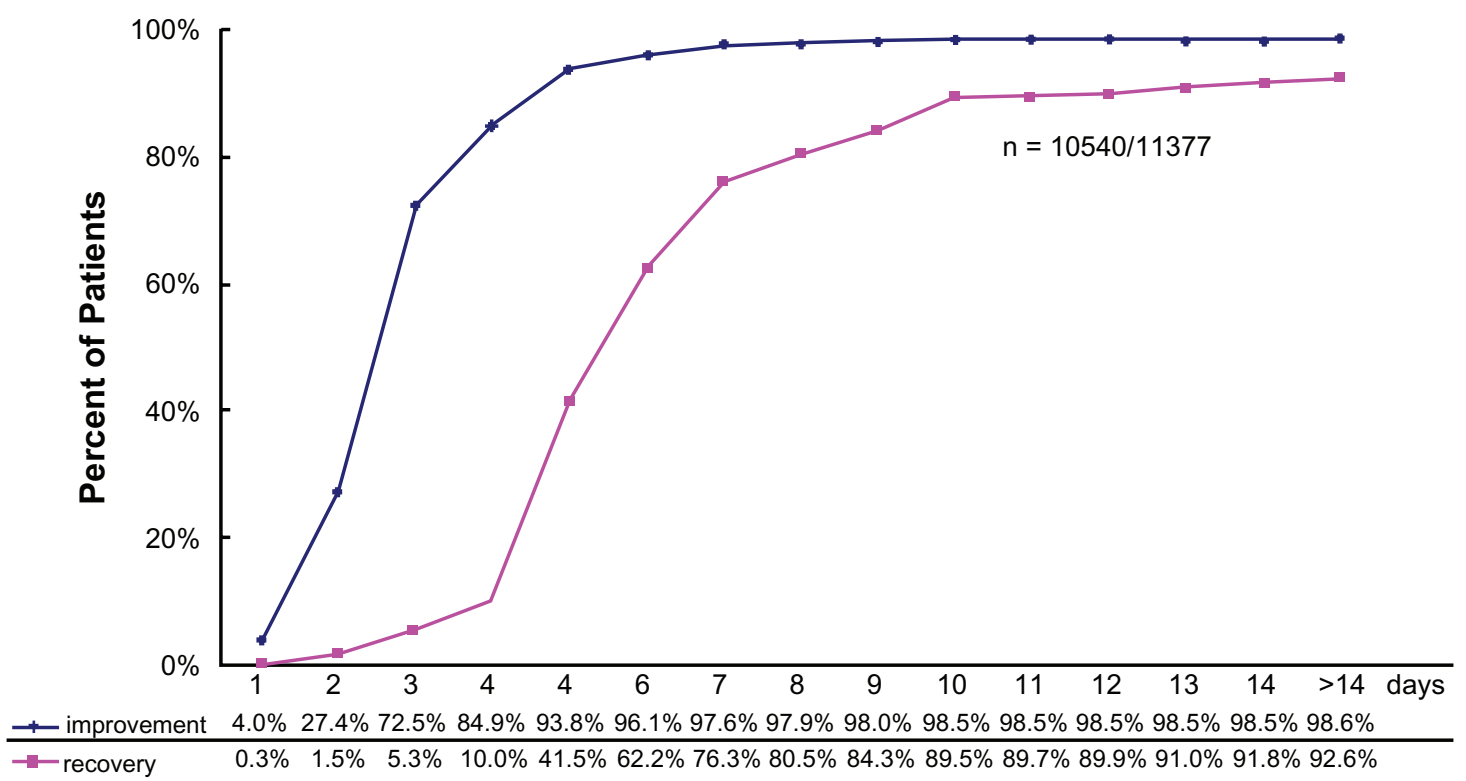

Figure 2 Duration until improvement and recovery of infection.

\section{Safety results}

AEs occurred in $0.82 \%(n=93 / 11,377)$ of patients during the observation period. The most frequently reported events were classed as "gastrointestinal disorders", followed by "nervous system disorders" and "psychiatric disorders". During the initial treatment period, symptoms such as nausea $(n=35 / 11,377,0.3 \%)$, vomiting $(n=22 / 11,377,0.2 \%)$, and dizziness $(\mathrm{n}=12 / 11,377,0.1 \%)$ were predominant.
In summary, 147 events were reported in 93 patients. The majority of outcomes of all AEs were categorized as "resolved" or "improved" (Table 3).

One individual subject experienced a treatment-emergent serious AE (SAE) which was also assessed as drug-related (serious adverse drug reactions, SADR). The SADR (dyspnea) required hospitalization/prolongation of hospitalization and was resolved at the end of the observation period.

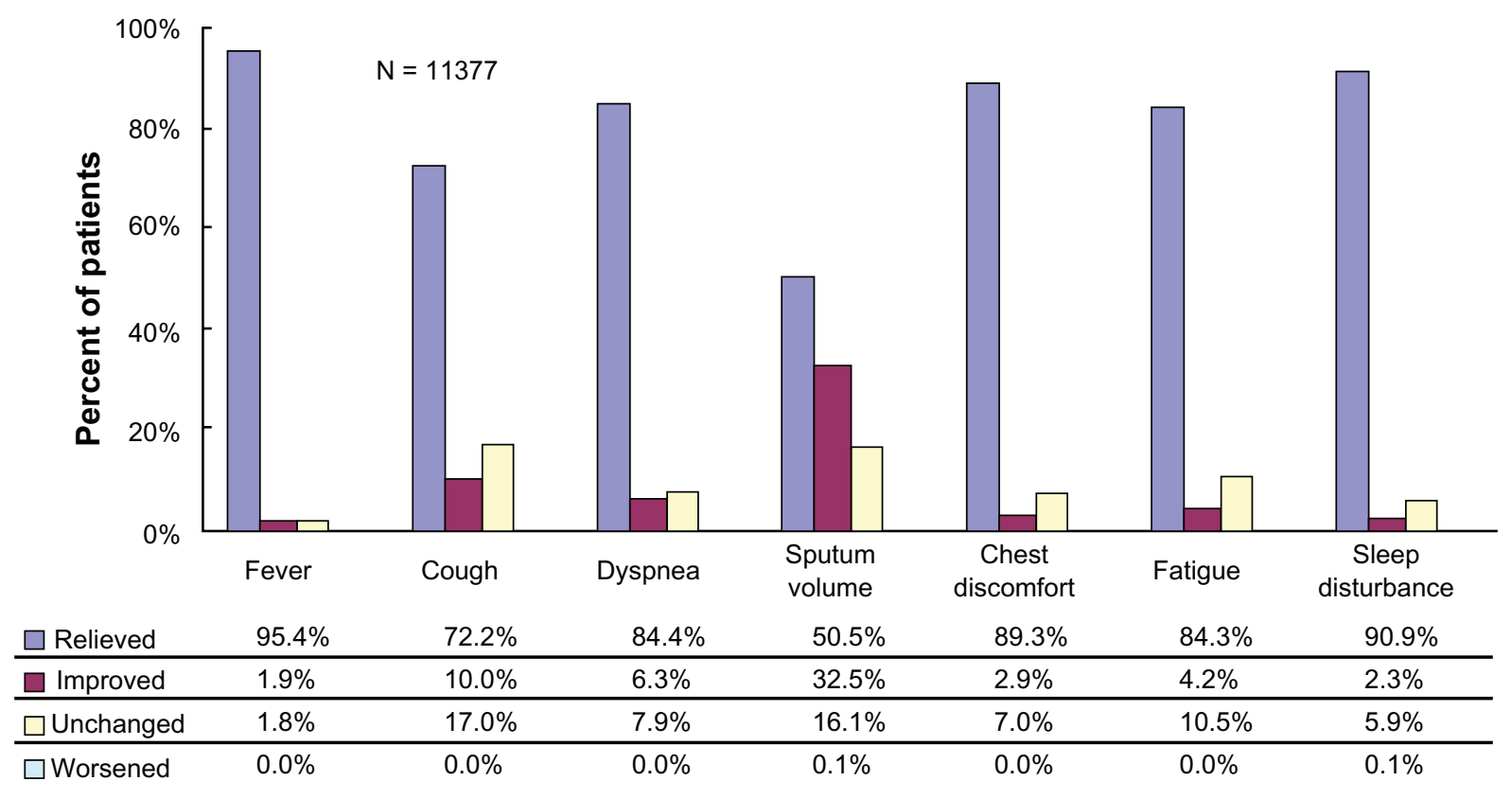

Figure 3 Course of symptoms from initial visit to last follow-up visit (only patients with symptom at initial visit). 


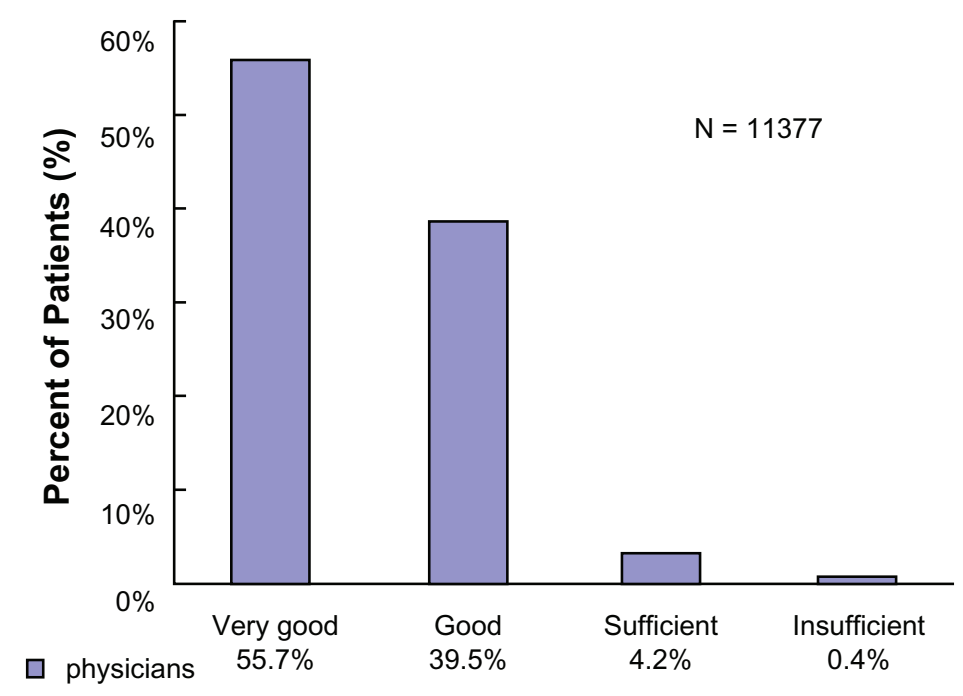

Figure 4 Physicians' overall assessment of tolerability.

\section{Discussion}

AECB are a major cause of morbidity and mortality. Bacterial pathogens are implicated in about half the episodes of AECB. Empirical antibacterials have a significant benefit in AECB; however, several recent developments have considerably complicated antibacterial choice for this condition. New fluoroquinolone antibacterials introduced in the last decade are theoretically well suited for the treatment of AECB, as the in vitro antimicrobial spectrum of these drugs includes all the major pathogens involved.

The pharmacokinetic and pharmacodynamic properties of the new fluoroquinolones are superior to many other antibacterials used to treat AECB. Patients with AECB are a heterogeneous population who should be stratified in order to choose appropriately empirical antibacterial therapy. It is important to consider that bacterial resistance varies geographically at national, regional and community levels. Currently, fluoroquinolone resistance in respiratory pathogens is low, but there are strong links between rates of consumption and resistance. ${ }^{5}$ Significant relationships between increased fluoroquinolone use and reduced percentage susceptibility have also been demonstrated for a group of 11 bacterial pathogens $(P<0.05) .{ }^{6}$ The studies for the new fluoroquinolone, moxifloxacin, have demonstrated that mutations in the target genes require more than one mutation.

Table 3 Patient-based incidence rate of adverse events

\begin{tabular}{ll}
\hline & $\mathbf{N}=1 \mathrm{I}, 377 \mathrm{n}(\%)$ \\
\hline Any adverse events & $93(0.82)$ \\
Adverse drug reaction & $76(0.67)$ \\
Serious adverse events & $\mathrm{I}(0.0 \mathrm{I})$ \\
Serious adverse drug reaction & $\mathrm{I}(0.0 \mathrm{I})$ \\
\hline
\end{tabular}

Theoretically, this requirement, in combination with the favorable pharmacokinetic and pharmacodynamic properties of fluoroquinolones (large AUIC and $\mathrm{C}_{\max }$ to $\mathrm{MIC}_{90}$ ratios), should delay the emergence of resistance to moxifloxacin.

A single strategy for antibacterial therapy for all episodes of AECB is therefore likely to lead to inadequate or excessive antibacterial treatment in many patients. Recently, a stratification approach to antibacterial therapy of AECB has been advocated. ${ }^{78}$ Significant risk factors that predict poor outcome of AECB episodes and failure of antibacterial treatments have been recently identified. These risk factors include exacerbations characterized by multiple symptoms (increased dyspnea, sputum production and sputum purulence), older age ( $>65$ years), underlying severe obstructive lung disease, and frequent $(\geq 4)$ exacerbations in the previous year and the presence of coexistent cardiac disease..$^{7-9}$

In our study, chronic bronchitis was diagnosed in $16.2 \%(\mathrm{n}=1843 / 11,377), 38.0 \%(\mathrm{n}=4323 / 11,377), 21.4 \%$ $(\mathrm{n}=2435 / 11,377)$, and $22.4 \%(\mathrm{n}=2548 / 11,377)$ of the patients $<1$ year, 1 to 5 years, $>5$ to 10 years, and more than 10 years prior to study start. Stratified analysis revealed that in subgroups with male patients, greater proportions of patients with longer duration of AECB were observed compared to subgroups with female patients. Other analyses indicated that in subgroups with older patients ( $\geq 65$ years), unemployed patients and past smokers comparatively, greater proportions of patients with longer duration of AECB were observed compared with younger patients ( $<65$ years), employed patients, and current/nonsmokers. In the 12-month period prior to study start, $46.9 \%(n=5336 / 11,377)$ of patients had one or two episodes of AECB, whereas three or more episodes were reported in $38.1 \%$ $(n=4335 / 11,377)$ of patients. Comparing these data to a similar 
analysis of European data of the GIANT study, more European patients suffered from chronic bronchitis for more than 10 years, the proportion of female patients and patients $\geq 65$ years was higher, and fewer patients were nonsmokers. ${ }^{10}$

At the end of the observation period, mainly positive assessments were given: for $95.8 \%(n=10,903 / 11,377)$ of patients effectiveness was rated as "very good" or "good". The data show that physicians were "very satisfied" or "satisfied" with the therapeutic effect in $98.1 \%(n=11,165 / 11,377)$ of patients. Besides, moxifloxacin treatment was considered to be well tolerated, rated in $95.2 \%(n=10,834 / 11,377)$ of patients as "very good" and "good". AEs occurred in $0.82 \%$ ( $n=93 / 11,377)$ of patients during the observation period. The majority of outcomes of all AEs were categorized as "resolved" or "improved". Interestingly, Chinese physicians reported fewer adverse events than their European colleagues ( $2.6 \%$ of European patients suffered from an adverse event). ${ }^{4}$ The results of this noninterventional study are consistent with the findings from prior randomized controlled trials, showing that AECB treatment with moxifloxacin at a dose of $400 \mathrm{mg}$ is highly effective. Compared with other standard antibiotic therapies, treatment with moxifloxacin clearly resulted in higher patient and physician satisfaction.

The study included a large number of the AECB patients in China treated with moxifloxacin and was conducted under daily practice conditions. Patient recall may have limited the results of previous AECB treatment for number of days for which daily-life activities were affected and the number of nights with sleep disturbance. Other potential limitations are the open-label, noncontrolled design of the study and the lack of bacteriological testing to confirm diagnoses. In general, the high effectiveness and safety of moxifloxacin was demonstrated in the treatment of acute exacerbation of chronic bronchitis, which is identical to most of the results from randomized, controlled studies. ${ }^{4,11,12}$

\section{Conclusion}

In conclusion, moxifloxacin was efficacious and well tolerated in Chinese patients suffering from AECB. The fast speed of the drug's onset of action was associated with rapid improvement of clinical parameters.

Clinical Epidemiology

\section{Publish your work in this journal}

Clinical Epidemiology is an international, peer-reviewed, open access journal focusing on disease and drug epidemiology, identification of risk factors and screening procedures to develop optimal preventative initiatives and programs. Specific topics include: diagnosis, prognosis, treatment, screening, prevention, risk factor modification, systematic

\section{Acknowledgments}

The authors are grateful to Marc Miravitlles, Antonio Anzueto, Santiago Ewig, and Delfino Legnani (global GIANT study scientific committee) for their pivotal role in study design and implementation. Bayer Healthcare Company Ltd. provided funding for this study and for the preparation of the manuscript.

\section{Disclosures}

None of the authors declare conflicts of interest.

\section{References}

1. American Thoracic Society. Standards for the diagnosis and care of patients with chronic obstructive pulmonary disease. Am J Respir Crit Care Med. 1995;152(suppl S):77-121.

2. Spencer S, Jones PW, Time course of recovery of health status following an infective exacerbation of chronic bronchitis. Thorax. 2003;58: 589-593.

3. Miravitlles M, Ferrer M, Pont A, et al. Effect of Exacerbations on quality of life in patients with chronic obstructive pulmonary disease: 2 year follow up study. Thorax. 2004;59:387-395.

4. Miravitlles M, Molina J, Brosa M. Clinical efficacy of moxifloxacin in treatment of exacerbations of chronic bronchitis: a systematic review and meta-analysis. Arch Bronconeumol. 2007;43:22-28.

5. Reinert RR, Ringelstein A, van der Linden M, et al. Molecular epidemiology of macrolide-resistant Streptococcus pneumoniae isolates in Europe. J Clin Microbiol. 2005;43:1294-300.

6. Zervos MJ, Hershberger E, Nicolau DP, et al. Relationship between fluoroquinolone use and changes in susceptibility to fluoroquinolones of selected pathogens in 10 United States teaching hospitals, 1991-2000. Clin Infect Dis. 2003;37:1643-1648.

7. Sethi S. Etiology and management of infections in chronic obstructive pulmonary disease. Clin Pulm Med. 1999;6:327-332.

8. Balter MS. Recommendations on the management of chronic bronchitis: a practical guide for Canadian physicians. Can Med Assoc J. 1994;151:5-23.

9. Grossman R, Mukherjee J, Vaughan D, et al. A1-year community-based health economic study of ciprofloxacin vs usual antibiotic treatment in acute exacerbations of chronic bronchitis. Chest. 1998;113:131-141.

10. Miravitlles M, Anzueto A, Ewig S, et al. Characterisation of exacerbations of chronic bronchitis and COPD in Europe: the GIANT study. Ther Adv Respir Dis. In press.

11. Wilson R, Allegra L, Huchon G, et al. Short-term and long-term outcomes of moxifloxacin compared to standard antibiotic treatment in acute exacerbations of chronic bronchitis. Chest. 2004;125:953-964.

12. Min Zhang, Xin Zhou, Xingyi Zhang, et al. Short and long term efficacy observation of moxifloxacin in the treatment of acute exacerbation of chronic obstructive pulmonary disease. Chinese Journal of Infection and Chemotherapy. 2007;7:313-317.

reviews, risk \& safety of medical interventions, epidemiology \& biostatical methods, evaluation of guidelines, translational medicine, health policies \& economic evaluations. The manuscript management system is completely online and includes a very quick and fair peerreview system, which is all easy to use. 